\title{
Análise dos programas de incentivo fiscal do estado do Rio Grande do Sul Fundopem/RS e Integrar/RS para uma cooperativa do Corede Nordeste
}

\author{
Douglassi Negri" \\ Eduardo Belisário Finamore***
}

\begin{abstract}
Resumo
Este artigo tem por objetivos analisar e demonstrar a importância e a efetividade dos incentivos fiscais Fundopem/RS e Integrar/RS, por meio do impacto gerado no fluxo de caixa do projeto de expansão de uma cooperativa, localizada no norte do Rio Grande do Sul, de agroindustrialização do milho, transformando-o em xarope para a indústria de doces e balas do estado. Verificou-se que os incentivos fiscais apresentam impactos positivos significativos, medidos pelos indicadores econômicos e financeiros da taxa interna de retorno (TIR) e do valor presente líquido (VPL). A riqueza gerada pelo projeto de investimento de 40 milhões de reais, sem os incentivos fiscais, medida pelo VPL, foi de $\mathrm{R} \$ 90.629 .555,89$, com uma rentabilidade de $36,26 \%$ de TIR, considerando um custo de oportunidade (CO) de $8 \%$ ao ano. O enquadramento no Fundopem/RS beneficiou a empresa com a geração de uma riqueza extra de $R \$ 9.920 .051,72$ (VPL de $R \$ 100.549 .607,61$ e TIR de 46,13\%), e o enquadramento ao Integrar/RS gerou um riqueza extra para os sócios da cooperativa de $\mathrm{R} \$$ 16.829.708,60 (VPL de R\$107.459.264,49 e TIR de 46,47\%).
\end{abstract}

Palavras-chave: Fundopem/RS. Incentivos fiscais. Integrar/RS.

* Graduado em Administração pela Faculdade de Ciências Econômicas, Administrativas e Contábeis da Universidade de Passo Fundo (UPF). E-mail: douglassi@outlook.com

** Doutor em Economia Aplicada pela Universidade Federal de Viçosa. Professor da Faculdade de Ciências Econômicas, Administrativas e Contábeis da Universidade de Passo Fundo (UPF). E-mail: finamore@upf.br

http://dx.doi.org/10.5335/rtee.v24i50.8960

Submissão: 23/08/2017. Aceite: 26/02/2018. 


\section{Introdução}

O Fundo Operação Empresa do Estado do Rio Grande do Sul (Fundopem/RS) foi o primeiro programa de incentivo financeiro para o aumento da produção industrial no estado, criado em 1972 por meio da Lei n ${ }^{\circ}$ 6.497 (RIO GRANDE DO SUL, 1972). Ao longo do tempo, sofreu diversas alterações, passando por diferentes cenários políticos do estado, e teve a última alteração feita em 2011 por meio das Leis $\mathrm{n}^{\circ} 13.708$ (RIO GRANDE DO SUL, 2011a) e $\mathrm{n}^{\circ} 13.843$ (RIO GRANDE DO SUL, 2011b), regulamentadas pelo Decreto $\mathrm{n}^{\circ} 49.205$ (RIO GRANDE DO SUL, 2012). Atualmente este incentivo é o de diferimento do pagamento do imposto sobre circulação de mercadorias e serviços (ICMS) incremental pelas empresas apoiadas. Complementando o Fundopem/RS, foi criado em 2003, pela Lei ${ }^{\circ} 11.916$ (RIO GRANDE DO SUL, 2003), o programa de harmonização do desenvolvimento industrial do estado do Rio Grande do Sul, chamado de Integrar/RS, que é a principal ferramenta de incentivo fiscal do estado. O Integrar/RS é um abatimento do ICMS incremental e tem como diretrizes a descentralização estratégica da produção industrial, a redução de desigualdades regionais, o aumento da competitividade das atividades industrial e agroindustrial. Também é utilizado como arma na guerra fiscal entre os estados brasileiros.

$\mathrm{O}$ incentivo tem condições pactuadas em um acordo, e as empresas beneficiadas só podem frui-lo após cumprirem sua parte do acordo firmado, que é a de realizar investimentos, aumentar o quadro de funcionários e promover o desenvolvimento da região. Em síntese, o valor do incentivo concedido pelo estado é oriundo do ICMS incremental, isto é, o ICMS que a empresa tende a criar devido aos novos investimentos.

Este artigo tem por objetivos analisar e demonstrar a importância e a efetividade dos incentivos fiscais Fundopem/RS e Integrar/RS, por meio do impacto gerado no fluxo de caixa do projeto de expansão de uma cooperativa, localizada no Norte do Rio Grande do Sul, de agroindustrialização do milho, transformando-o em xarope para a indústria de doces e balas do estado. Para tanto, utilizaram-se os indicadores econômicos valor presente líquido (VPL) e taxa interna de retorno (TIR), e o fluxo de caixa projetado e a legislação observada foram do ano de 2014.

O trabalho é composto por quatro seções. A primeira seção oferece uma descrição geral dos critérios e fatores para enquadramento de projetos no Fundopem/RS e no Integrar/RS; a seção seguinte mostra os procedimentos metodológicos adotados neste estudo; a terceira seção apresenta os resultados alcançados; e, na última seção, estão algumas conclusões do trabalho realizado. 


\section{Procedimentos para obtenção do Fundopem/RS e do Integrar/RS}

Esta seção faz uma descrição geral dos procedimentos, critérios e fatores para enquadramento no Fundopem/RS e no Integrar/RS, e informações mais detalhadas podem ser obtidas no endereço eletrônico da Sala do Investidor da Secretaria do Desenvolvimento Econômico, Ciência e Tecnologia do estado do Rio Grande do Sul. O processo de concessão do incentivo inicia com a solicitação da empresa requerente, por meio do encaminhamento de uma carta-consulta à Coordenadoria Adjunta da Central do Sistema Estadual para Atração e Desenvolvimento de Atividades Produtivas.

A carta-consulta tem como objetivos a apresentação e a verificação do projeto de investimento. Analisa-se se o projeto atende às normas vigentes, conforme dispõem as resoluções normativas. Com a confirmação da possibilidade de enquadramento do projeto, é necessário que a empresa apresente um projeto mais detalhado, isso acontece por meio do roteiro de projeto, disponibilizado pela secretaria de desenvolvimento estadual.

O limite para concessão do benefício é de até $9 \%$ do faturamento bruto incremental, limitado a um mínimo de $35 \%$ e ao máximo de $90 \%$ do ICMS incremental mensal, no caso de empresas industriais, e a um mínimo de $45 \%$ e ao máximo de $100 \%$ do ICMS incremental mensal, no caso de cooperativas de produtores rurais com atividade industrial.

O Quadro 1 mostra a pontuação para enquadramento dos projetos que regula a atribuição de pontos segundo a avaliação do grau do ajustamento de cada projeto. A empresa recebe uma pontuação relativa ao somatório dos sete critérios estabelecidos, sendo a pontuação mínima 40 pontos e a máxima 115. Para obter a pontuação de um projeto, é necessário analisar os fatores que influenciam os setes critérios de enquadramento.

A pontuação relativa ao critério 1 - setores estratégicos - é analisada de acordo com a Tabela de Enquadramento instituída pela Resolução Normativa ${ }^{\circ} 3$ (RIO GRANDE DO SUL. 2016), de 10 de setembro de 2012, que identifica as atividades econômicas em cada setor estratégico. São três os grandes setores estabelecidos por esses critérios: prioritários, preferenciais e especiais (PPEs), podendo receber uma pontuação de 60,55 e 50 pontos, respectivamente.

A empresa é enquadrada no critério 2 se for fornecedora das empresas classificadas nos setores estratégicos, que são PPEs; ou seja, a empresa que tiver como atividades principais a produção e a comercialização de insumos e bens para as empresas estratégicas enquadradas no critério 1 recebe 40 pontos.

Teoria e Evidência Econômica - a. 24, n. 50, p. 89-112, jan./jun. 2018 
Quadro 1 - Pontuação para enquadramento dos projetos no Fundopem/RS

\begin{tabular}{|l|c|c|}
\hline \multicolumn{1}{|c|}{ CRITÉRIOS } & \multicolumn{2}{|c|}{ PONTUAÇÃO DO PROJETO } \\
\hline \multirow{2}{*}{1 - SETORES ESTRATÉGICOS } & Prioritários & 60 \\
\cline { 2 - 3 } & Preferenciais & 55 \\
\cline { 2 - 3 } & Especiais & 50 \\
\hline \multirow{2}{*}{2 - FORNECEDORA DE PPES } & 40 \\
\hline \multirow{2}{*}{3 - OUTROS SETORES INDUSTRIAIS } & Alta & 25 \\
\hline \multirow{3}{*}{4 - INTENSIDADE TECNOLÓGICA } & Média-alta & 30 \\
\cline { 2 - 3 } & Média-baixa & 25 \\
\cline { 2 - 3 } & Baixa & 10 \\
\hline \multirow{2}{*}{5 -ARRANJO PRODUTIVO LOCAL } & Enquadrado & 10 \\
\cline { 2 - 3 } & Reconhecido & 10 \\
\hline 6 - EMPREGOS & & 10 \\
\hline 7 - COOPERATIVA OU CENTRAL DE COOPERATIVAS DE PRODUTORES RURAIS & \\
\hline
\end{tabular}

Fonte: adaptado da Secretaria do Desenvolvimento Econômico, Ciência e Tecnologia (RIO GRANDE DO SUL, 2016).

Caso a empresa não seja enquadrada nos itens listados, recebe 25 pontos, referentes ao critério 3 , outros setores industriais. A pontuação do critério 4 , intensidade tecnológica, prioriza setores que apresentam mais pesquisa e desenvolvimento tecnológicos e obedece aos critérios adotados pela Organização para a Cooperação e Desenvolvimento Econômico. O projeto recebe a pontuação no critério 5, arranjo produtivo local (APL), se pertencer a um APL enquadrado ou a um APL reconhecido. No critério 6 - empregos -, a empresa recebe 10 pontos se gerar o número mínimo de empregos estabelecido de acordo com o porte da empresa e com a qualidade da massa salarial. Quanto ao critério 7, caso o empreendimento seja uma cooperativa ou uma central de cooperativas de produtores rurais, recebe 10 pontos, mas não há enquadramento com base no critério 6 . Ou seja, independentemente do número de empregos gerado no projeto de investimento a ser implantado, a cooperativa recebe 10 pontos no quesito.

Após estabelecida a pontuação de acordo com os sete critérios descritos anteriormente, definem-se as condições de financiamento, com base no Quadro 2. O porte da empresa, para fins de aplicação do disposto no Quadro 11, é determinado segundo os parâmetros das linhas de financiamento de longo prazo adotados pelo Banco Nacional de Desenvolvimento Econômico e Social. 
Quadro 2 - Faixas e condições de financiamento no Fundopem/RS

\begin{tabular}{|c|c|c|c|c|c|c|c|c|c|c|}
\hline \multirow{2}{*}{ Faixa } & \multirow{2}{*}{ Pontuação } & \multirow{2}{*}{$\begin{array}{c}\text { Incentivo } \\
\text { básico }\end{array}$} & \multicolumn{5}{|c|}{ Juros (\% a.a.) } & \multicolumn{4}{c|}{ Prazo (meses) } \\
\cline { 5 - 13 } & & & Micro & Pequena & Média & Média-grande & Grande & Fruição & Carência & Amortização \\
\hline 1 & $35-40$ & $35 \% \cdot 40 \%$ & 1,00 & 1,25 & 1,50 & 1,75 & 2,00 & 78 & 48 & 78 \\
\hline 2 & $45-55$ & $45 \% \cdot 55 \%$ & 0,75 & 1,00 & 1,25 & 1,50 & 1,75 & 84 & 54 & 84 \\
\hline 3 & $60-70$ & $60 \% \cdot 70 \%$ & 0,50 & 0,75 & 1,00 & 1,25 & 1,50 & 90 & 60 & 90 \\
\hline 4 & $75-85$ & $75 \%$ & 0,25 & 0,50 & 0,75 & 1,00 & 1,25 & 96 & 60 & 96 \\
\hline 5 & $>85$ & $75 \%$ & 0,00 & 0,25 & 0,50 & 0,75 & 1,00 & 96 & 60 & 96 \\
\hline
\end{tabular}

Fonte: Secretaria do Desenvolvimento Econômico, Ciência e Tecnologia (RIO GRANDE DO SUL, 2016).

Há a possibilidade ainda de duas formas de alavancagem do percentual de incentivo de diferimento do ICMS incremental a pagar. A primeira forma de alavancagem do percentual de incentivo dos projetos que não atingirem $75 \%$ é ter o incentivo aumentado em até 15 pontos percentuais, de acordo com a origem do investimento fixo, desde que após a alavancagem o incremento continue dentro do limite de $75 \%$ do ICMS incremental. A segunda forma de alavancagem é dar às cooperativas até $100 \%$ do ICMS incremental e às demais empresas $90 \%$, conforme a média de aquisição de insumos dentro do estado. $\mathrm{O}$ incentivo em 15 pontos percentuais é dado caso as aquisições no estado de insumos e serviços superarem a média do setor.

O Fundopem/RS é um incentivo dado pelo financiamento do ICMS a pagar, conforme um sistema de amortização constante (SAC), com período de carência e sem pagamento de juros durante essa carência. O incentivo máximo é calculado pelo limite do ICMS incremental gerado, que vai sendo acumulado durante o período de fruição. O prazo de fruição varia de 78 a 96 meses. Cabe dizer que é calculado um valor mensal do ICMS incremental gerado pela empresa neste período de fruição, limitado ao valor do investimento realizado pela empresa. Essas parcelas mensais calculadas têm, então, de ser pagas pelas empresas depois do período de carência que varia de 48 a 60 meses. Durante o período de carência, não se paga os juros que variam de zero a dois por cento. A amortização do ICMS devido deve ser feita no prazo de 78 a 96 meses.

Além do financiamento do ICMS incremental a pagar, dado pelo Fundopem/ $\mathrm{RS}$, as empresas ainda podem solicitar o incentivo do Integrar/RS que concede abatimento na prestação do financiamento gerado pelo Fundopem/RS; o benefício do Integrar/RS foi criado em 2003, pelo governador Germano Rigotto, e desde então desempenha um importante papel na atração e na retenção de novos investimentos no estado. $\mathrm{O}$ Integrar/RS permite à empresa abater uma porcentagem na prestação 
referente ao financiamento gerado pelo incentivo do Fundopem/RS, sendo, assim, caracterizado como um subsídio para a empresa.

O percentual de subsídio dado às empresas depende do índice de desenvolvimento social do município ou da região (Idese) em que as empresas vão se instalar. O valor desse índice, seja do município, seja da região de planejamento (Conselho Regional de Desenvolvimento - Corede), deve ser menor do que a média estadual de 0,78. Para ser beneficiado com esse incentivo, também se levam em consideração sete critérios, conforme Quadro 3, sendo o Idese o de maior peso.

$\mathrm{O}$ benefício fiscal do Integrar/RS concede um abatimento na prestação gerada pelo Fundopem/RS, caracterizado como um subsídio cujo valor de abatimento concedido varia de $10 \%$ a $90 \%$. Os indicadores de desenvolvimento socioeconômico e abatimentos das regiões e dos municípios do estado, bem como as informações detalhadas para se verificar a pontuação obtida por um projeto, conforme descritos no Quadro 3, podem ser obtidos no site da secretaria de investimento.

Quadro 3 - Pontuação para enquadramento dos projetos no Integrar/RS

\begin{tabular}{|c|c|c|}
\hline Critério & \multicolumn{2}{|c|}{ Pontuação } \\
\hline \multirow{2}{*}{1 - ÍNDICE DE DESENVOLVIMENTO INTEGRAR/IDESE } & Máxima & $80 \%$ \\
\hline & Mínima & $10 \%$ \\
\hline \multirow{2}{*}{2 - GERAÇÃO DE EMPREGO } & Máxima & $10 \%$ \\
\hline & Mínima & $2 \%$ \\
\hline \multirow{2}{*}{3 - QUALIDADE DA MASSA SALARIAL } & Máxima & $10 \%$ \\
\hline & Mínima & $2 \%$ \\
\hline \multirow{3}{*}{4 - SETORES ESTRATÉGICOS } & Prioritários & $15 \%$ \\
\hline & Preferenciais & $10 \%$ \\
\hline & Especiais & $5 \%$ \\
\hline 5 - FORNECEDORADE PPE & Fixa & $3 \%$ \\
\hline \multirow{2}{*}{6 - IMPACTO AMBIENTAL } & Máxima & $5 \%$ \\
\hline & Mínima & $3 \%$ \\
\hline 7 - DISTRITO INDUSTRIAL CONTÍGUO À PRISÃO & Fixa & $5 \%$ \\
\hline \multicolumn{2}{|l|}{ TOTAL } & $90 \%$ \\
\hline
\end{tabular}

Fonte: adaptado da Secretaria do Desenvolvimento Econômico, Ciência e Tecnologia (RIO GRANDE DO SUL, 2016).

O conjunto dessas análises resulta no parecer técnico sobre o projeto, que sugere ou não o enquadramento no Fundopem/RS e no Integrar/RS, informando a pontuação atingida e os parâmetros concessórios correspondentes. 


\section{Procedimentos metodológicos}

A metodologia básica utilizada por economistas para avaliar projetos é a análise de custo e benefício com o uso de indicadores, como VPL e TIR. Os cálculos e as regras de decisão desses indicadores são largamente divulgados em livros de finanças de forma que não são retomados neste trabalho. No entanto, cabe ressaltar que, conforme Silva Neto (1994), de acordo com os fundamentos teóricos que formam os alicerces desse método de análise, apenas custos e benefícios que resultam da implantação de um determinado projeto devem ser considerados em uma análise empírica. Isso implica ser a análise de custo e benefício essencialmente uma técnica de equilíbrio parcial, dado que todas as outras variáveis que não se relacionarem com o projeto em questão devem ser ignoradas.

A operacionalização do princípio referido é feita em dois passos:

- em primeiro lugar, na avaliação ex-ante, o analista identifica os fluxos de custos e benefícios que são adicionados, caso o projeto venha a ser implementado;

- em segundo, a avaliação ex-post verifica se os objetivos determinados por ocasião da avaliação ex-ante foram alcançados. Feita a identificação, os custos e benefícios são quantificados em termos monetários.

Em resumo, a identificação de custos e benefícios é sempre a primeira fase do trabalho analítico. Para que ela seja consistente, é preciso comparar a situação do projeto que está sendo avaliado com a situação que prevaleceria sem ele. Em outras palavras, é necessário identificar custos e benefícios que resultam da implementação do projeto e compará-los com aqueles que ocorreriam em sua ausência. Somente assim é possível estimar custos e benefícios adicionados pelo projeto.

Neste artigo, considerou-se que a situação sem o projeto deve ser avaliada pelo fluxo de caixa do projeto de investimento, sem considerar os benefícios fiscais; e a situação com o projeto, avaliada pelo fluxo de caixa com a inclusão dos benefícios fiscais. Os números para compilação dos dados foram obtidos por meio de pesquisa realizada com os diretores da cooperativa, com valores referentes ao ano de 2014.

\section{Resultados}

A seguir, são apresentados os resultados da análise do benefício do Fundopem/ RS e do Integrar/RS a serem obtidos com o projeto de expansão de uma cooperativa localizada no município de Ibiraiaras. Trata-se de um projeto de industrialização

Teoria e Evidência Econômica - a. 24, n. 50, p. 89-112, jan./jun. 2018 
do milho, transformando-o em xarope de óleo de milho para a indústria de doces e balas do estado. O projeto da nova fábrica ainda está em fase de elaboração, e os números apresentados são estimativas preliminares. $\mathrm{O}$ objetivo principal do cálculo foi quantificar o retorno do investimento antes e depois dos incentivos fiscais, de forma a permitir à diretoria a tomada de decisão sobre o investimento, sobre o acesso aos incentivos fiscais e sobre a elaboração de um projeto com laudos técnicos de engenharia, de consultorias econômica e jurídica, para ser encaminhado para a assembleia geral da cooperativa.

\section{Descrição econômico-financeira da agroindústria sem incentivo governamental}

Esta seção apresenta os resultados da análise de benefício alcançados sem considerar o benefício do Fundopem/RS e do Integrar/RS. Ou seja, trata-se da avaliação do projeto de industrialização do milho com o investimento realizado apenas com capital próprio. Como apontado anteriormente, os dados gerados são estimativas empíricas fornecidas pela diretoria da cooperativa e servem apenas como baliza para o aprofundamento dos estudos técnicos necessários para a implementação do projeto.

O Quadro 4 mostra o fluxo de caixa mensal estimado, idealizado pela diretoria.

Quadro 4 - Fluxo de caixa mensal projetado da agroindústria

\begin{tabular}{|l|c|c|}
\hline \multicolumn{1}{|c|}{ Item } & Valor & Porcentagem \\
\hline Receita bruta & $\mathbf{R} \$ \mathbf{3 . 8 2 5 . 0 0 0 , 0 0}$ & $100 \%$ \\
ICMS & $\mathrm{R} \$ \mathbf{4 5 9 . 0 0 0 , 0 0}$ & $\mathbf{1 2 \%}$ \\
Receita líquida & $\mathrm{R} \$ 3.366 .000,00$ & $88 \%$ \\
Custo do Produto Vendido & $\mathbf{R} \mathbf{1 . 5 0 0 . 0 0 0 , 0 0}$ & $39,22 \%$ \\
Lucro bruto & $\mathrm{R} \$ 1.866 .000,00$ & $43,78 \%$ \\
Despesas operacionais sem depreciação & $\mathbf{R} \$ \mathbf{6 0 0 . 0 0 0 , 0 0}$ & $15,69 \%$ \\
Fluxo de caixa líquido & $\mathrm{R} \$ 1.266 .000,00$ & $28,1 \%$ \\
\hline
\end{tabular}

Fonte: dados da pesquisa.

O Quadro 5 apresenta o fluxo de caixa anual projetado para 20 anos, fruto do limite de pagamento dos financiamentos de ICMS a ser solicitado. Nesse caso, haveria a necessidade de se realizarem reinvestimentos ao longo do período. 
Atualmente, a cooperativa tem 5.519 sócios e um faturamento anual de $\mathrm{R} \$$ 144.059.746,00. Segundo os dirigentes da cooperativa, o investimento estimado necessário para a agroindustrialização de 100 toneladas de milho por dia, transformando-o em xarope de óleo de milho, seria de 40 milhões de reais. Para o processamento de 100 toneladas de milho por dia, trabalhando 30 dias por mês, estima-se um faturamento mensal de $\mathrm{R} \$$ 3.825.000,00 (Quadro 4). Para efeito de arrecadação, conforme o setor financeiro da cooperativa, o enquadramento da agroindústria seria por uma alíquota de ICMS de $12 \%$ sobre o faturamento. Por se tratar de uma nova unidade produtiva, todo o faturamento da agroindústria foi considerado como incremental e, portanto, alvo de benefício do Fundopem/RS e do Integrar/RS.

Quadro 5 - Fluxo de caixa estimado do projeto de agroindústria sem incentivo governamental

\begin{tabular}{|c|c|c|c|c|c|c|c|c|}
\hline Ano & Investimento & Receita & - ICMS (12\%) & - CPV & Lucro bruto & $\begin{array}{c}\text { Despesas } \\
\text { operacionais sem } \\
\text { depreciação }\end{array}$ & $\begin{array}{c}\text { Fluxo de caixa } \\
\text { bruto }\end{array}$ & $\begin{array}{c}\text { Fluxo de caixa } \\
\text { líquido }\end{array}$ \\
\hline ano 0 & - $R \$ 40.000 .000,00$ & & & & & & & - $R \$ 40.000 .000,00$ \\
\hline ano 1 & & $R \$ 45.900 .000,00$ & $R \$-5.508 .000,00$ & $R \$-18.000 .000,00$ & $\mathrm{R} \$ 22.392 .000,00$ & $\mathrm{R} \$ 7.200 .000,00$ & $R \$ 15.192 .000,00$ & $\mathrm{R} \$ 15.192 .000,00$ \\
\hline ano 2 & & $\mathrm{R} \$ 45.900 .000,00$ & $R \$-5.508 .000,00$ & $R \$-18.000 .000,00$ & $\mathrm{R} \$ 22.392 .000,00$ & $\mathrm{R} \$ 7.200 .000,00$ & $\mathrm{R} \$ 15.192 .000,00$ & $\mathrm{R} \$ 15.192 .000,00$ \\
\hline ano 3 & & $\mathrm{R} \$ 45.900 .000,00$ & $R \$-5.508 .000,00$ & $R \$-18.000 .000,00$ & $\mathrm{R} \$ 22.392 .000,00$ & $\mathrm{R} \$ 7.200 .000,00$ & $\mathrm{R} \$ 15.192 .000,00$ & $\mathrm{R} \$ 15.192 .000,00$ \\
\hline ano 4 & & $\mathrm{R} \$ 45.900 .000,00$ & $R \$-5.508 .000,00$ & $R \$-18.000 .000,00$ & $\mathrm{R} \$ 22.392 .000,00$ & $\mathrm{R} \$ 7.200 .000,00$ & $\mathrm{R} \$ 15.192 .000,00$ & $\mathrm{R} \$ 15.192 .000,00$ \\
\hline ano 5 & & $\mathrm{R} \$ 45.900 .000,00$ & $R \$-5.508 .000,00$ & $R \$-18.000 .000,00$ & $\mathrm{R} \$ 22.392 .000,00$ & $\mathrm{R} \$ 7.200 .000,00$ & $\mathrm{R} \$ 15.192 .000,00$ & $\mathrm{R} \$ 15.192 .000,00$ \\
\hline ano 6 & & $\mathrm{R} \$ 45.900 .000,00$ & $R \$-5.508 .000,00$ & $\mathrm{R} \$-18.000 .000,00$ & $\mathrm{R} \$ 22.392 .000,00$ & $\mathrm{R} \$ 7.200 .000,00$ & $\mathrm{R} \$ 15.192 .000,00$ & $\mathrm{R} \$ 15.192 .000,00$ \\
\hline ano 7 & & $\mathrm{R} \$ 45.900 .000,00$ & $R \$-5.508 .000,00$ & $R \$-18.000 .000,00$ & $\mathrm{R} \$ 22.392 .000,00$ & $\mathrm{R} \$ 7.200 .000,00$ & $R \$ 15.192 .000,00$ & $\mathrm{R} \$ 15.192 .000,00$ \\
\hline ano 8 & & $\mathrm{R} \$ 45.900 .000,00$ & $R \$-5.508 .000,00$ & $R \$-18.000 .000,00$ & $\mathrm{R} \$ 22.392 .000,00$ & $\mathrm{R} \$ 7.200 .000,00$ & $\mathrm{R} \$ 15.192 .000,00$ & $\mathrm{R} \$ 15.192 .000,00$ \\
\hline ano 9 & & $\mathrm{R} \$ 45.900 .000,00$ & $R \$-5.508 .000,00$ & $R \$-18.000 .000,00$ & $\mathrm{R} \$ 22.392 .000,00$ & $\mathrm{R} \$ 7.200 .000,00$ & $\mathrm{R} \$ 15.192 .000,00$ & $\mathrm{R} \$ 15.192 .000,00$ \\
\hline ano 10 & - $R \$ 40.000 .000,00$ & $R \$ 45.900 .000,00$ & $R \$-5.508 .000,00$ & $R \$-18.000 .000,00$ & $\mathrm{R} \$ 22.392 .000,00$ & $\mathrm{R} \$ 7.200 .000,00$ & $\mathrm{R} \$ 15.192 .000,00$ & - $R \$ 24.808 .000,00$ \\
\hline ano 11 & & $\mathrm{R} \$ 45.900 .000,00$ & $R \$-5.508 .000,00$ & $\mathrm{R} \$-18.000 .000,00$ & $\mathrm{R} \$ 22.392 .000,00$ & $\mathrm{R} \$ 7.200 .000,00$ & $\mathrm{R} \$ 15.192 .000,00$ & $\mathrm{R} \$ 15.192 .000,00$ \\
\hline ano 12 & & $\mathrm{R} \$ 45.900 .000,00$ & $\mathrm{R} \$-5.508 .000,00$ & $R \$-18.000 .000,00$ & $\mathrm{R} \$ 22.392 .000,00$ & $\mathrm{R} \$ 7.200 .000,00$ & $\mathrm{R} \$ 15.192 .000,00$ & $\mathrm{R} \$ 15.192 .000,00$ \\
\hline ano 13 & & $R \$ 45.900 .000,00$ & $R \$-5.508 .000,00$ & $R \$-18.000 .000,00$ & $\mathrm{R} \$ 22.392 .000,00$ & $\mathrm{R} \$ 7.200 .000,00$ & $R \$ 15.192 .000,00$ & $\mathrm{R} \$ 15.192 .000,00$ \\
\hline ano 14 & & $\mathrm{R} \$ 45.900 .000,00$ & $R \$-5.508 .000,00$ & $R \$-18.000 .000,00$ & $\mathrm{R} \$ 22.392 .000,00$ & $\mathrm{R} \$ 7.200 .000,00$ & $\mathrm{R} \$ 15.192 .000,00$ & $\mathrm{R} \$ 15.192 .000,00$ \\
\hline ano 15 & & $\mathrm{R} \$ 45.900 .000,00$ & $R \$-5.508 .000,00$ & $R \$-18.000 .000,00$ & $\mathrm{R} \$ 22.392 .000,00$ & $\mathrm{R} \$ 7.200 .000,00$ & $\mathrm{R} \$ 15.192 .000,00$ & $\mathrm{R} \$ 15.192 .000,00$ \\
\hline ano 16 & & $R \$ 45.900 .000,00$ & $R \$-5.508 .000,00$ & $R \$-18.000 .000,00$ & $\mathrm{R} \$ 22.392 .000,00$ & $\mathrm{R} \$ 7.200 .000,00$ & $\mathrm{R} \$ 15.192 .000,00$ & $\mathrm{R} \$ 15.192 .000,00$ \\
\hline ano 17 & & $\mathrm{R} \$ 45.900 .000,00$ & $R \$-5.508 .000,00$ & $R \$-18.000 .000,00$ & $\mathrm{R} \$ 22.392 .000,00$ & $\mathrm{R} \$ 7.200 .000,00$ & $\mathrm{R} \$ 15.192 .000,00$ & $\mathrm{R} \$ 15.192 .000,00$ \\
\hline ano 18 & & $\mathrm{R} \$ 45.900 .000,00$ & $R \$-5.508 .000,00$ & $\mathrm{R} \$-18.000 .000,00$ & $\mathrm{R} \$ 22.392 .000,00$ & $\mathrm{R} \$ 7.200 .000,00$ & $\mathrm{R} \$ 15.192 .000,00$ & $\mathrm{R} \$ 15.192 .000,00$ \\
\hline ano 19 & & $\mathrm{R} \$ 45.900 .000,00$ & $R \$-5.508 .000,00$ & $R \$-18.000 .000,00$ & $\mathrm{R} \$ 22.392 .000,00$ & $\mathrm{R} \$ 7.200 .000,00$ & $\mathrm{R} \$ 15.192 .000,00$ & $\mathrm{R} \$ 15.192 .000,00$ \\
\hline ano 20 & & $\mathrm{R} \$ 45.900 .000,00$ & $R \$-5.508 .000,00$ & $R \$-18.000 .000,00$ & $\mathrm{R} \$ 22.392 .000,00$ & $\mathrm{R} \$ 7.200 .000,00$ & $\mathrm{R} \$ 15.192 .000,00$ & $\mathrm{R} \$ 15.192 .000,00$ \\
\hline Total & - $\mathrm{R} \$ 80.000 .000,00$ & $\mathrm{R} \$ 918.000 .000,00$ & $R \$-110.160 .000,00$ & $R \$-360.000 .000,00$ & $\mathrm{R} \$ 447.840 .000,00$ & $\mathrm{R} \$ 144.000 .000,00$ & $R \$ 303.840 .000,00$ & $R \$ 223.840 .000,00$ \\
\hline
\end{tabular}

Fonte: dados da pesquisa.

Teoria e Evidência Econômica - a. 24, n. 50, p. 89-112, jan./jun. 2018 
Devido à falta de informações detalhadas sobre os itens específicos deste investimento, bem como sobre o tempo de vida útil de cada bem, optou-se por considerar a necessidade de um novo reinvestimento no décimo primeiro ano, de valor igual ao do investimento inicial do projeto (Quadro 5), procedimento de concordância com a diretoria financeira da cooperativa. A última linha do Quadro 5 mostra que, ao longo de 20 anos de planejamento do projeto, o faturamento total estimado seria de $R \$ 918.000 .000,00$, gerando um ICMS incremental de $\mathrm{R} \$ 110.160 .000,00$, com projeção de fluxo de caixa líquido de $\mathrm{R} \$ 223.840 .000,00$.

O Quadro 6 apresenta os indicadores utilizados para medir a viabilidade econômica do projeto. Para cálculo do VPL, utilizou-se um CO de 8\% ao ano, considerado uma taxa de juros de longo prazo; com isso, estima-se um VPL no valor de $\mathrm{R} \$ 90.629 .555,89$. A TIR do projeto foi avaliada em $36,26 \%$. Nota-se que, antes de o projeto receber o benefício, ele já pode ser considerado viável. O que se observa adiante é o quanto os benefícios do Fundopem/RS e do Integrar/RS podem alavancar a viabilidade desse projeto.

Quadro 6 - Indicadores de viabilidade da agroindústria sem incentivo

\begin{tabular}{|c|c|}
\hline VPL & $\mathrm{R} \$ 90.629 .555,89$ \\
\hline TIR & $36,26 \%$ \\
\hline CO & $8 \%$ \\
\hline
\end{tabular}

Fonte: dados da pesquisa.

\section{Mensuração do valor do benefício gerado pelo Fundopem/RS e pelo Integrar/RS}

O objetivo desta seção é avaliar o benefício a ser obtido por meio do Fundopem/RS e do Integrar/RS para a agroindústria. No caso de investimentos em uma cooperativa, há como benefício a utilização de $100 \%$ do ICMS incremental para financiamento (diferimento do pagamento) com o governo do estado sendo limitado a $9 \%$ do faturamento bruto incremental. Assim, mesmo que a alíquota de ICMS seja de $12 \%$, o limite para financiamento via Fundopem/RS é de $9 \%$, ou seja, R\$ $344.250,00$.

Para efeito de simulação, considerou-se que todos os fluxos de entrada e saída de recursos do caixa são incrementais, não se estão o faturamento atual da cooperativa agrícola em questão. O custo de produção estimado pela diretoria da cooperativa é de $R \$ 500,00$ por tonelada de milho processada, e as despesas operacionais, 
de $\mathrm{R} \$ 200,00$ por tonelada. O benefício observado foi de $75 \%$ de $\mathrm{R} \$ 459.000,00$ de ICMS incremental, o que gera a possibilidade de financiamento de $\mathrm{R} \$ 344.250,00$. Observando o benefício do Integrar/RS, como é descrito adiante, ele foi de 50\% da amortização referente ao financiamento do Fundopem/RS.

O Quadro 7 representa a forma de amortização utilizada no financiamento, ou seja, o SAC com carência e sem pagamento de juros na carência. Como se observa, o valor de cada parcela de ICMS incremental anual é de 4,13 milhões de reais, obtidos pela multiplicação de 12 meses de $\mathrm{R} \$ 344.250,00$. No período de carência, o saldo devedor é corrigido em $1 \%$ ao ano. Após a carência, o valor acumulado é amortizado em 8 anos. O Quadro 7 mostra ainda o valor da prestação, que incorpora, além da amortização do valor de ICMS financiado, o valor dos juros cobrado, conforme o enquadramento legal. O saldo devedor vai diminuindo à medida que os pagamentos da amortização são efetuados.

Quadro 7 - Amortização do Fundopem/RS no primeiro ano

\begin{tabular}{|c|c|c|c|c|}
\hline$T$ & Prestação & Amortização & Juros & Saldo devedor \\
\hline 0 & & & & $4.131 .000,00$ \\
\hline 1 & & & & $4.172 .310,00$ \\
\hline 2 & & & & $4.214 .033,10$ \\
\hline 3 & & & & $4.256 .173,43$ \\
\hline 4 & & & & $4.298 .735,17$ \\
\hline 5 & & & $43.417,23$ & $4.341 .722,52$ \\
\hline 6 & $586.132,54$ & $542.715,31$ & $37.990,07$ & $3.799 .007,20$ \\
\hline 7 & $580.705,39$ & $542.715,31$ & $32.562,92$ & $3.256 .291,89$ \\
\hline 8 & $575.278,23$ & $542.715,31$ & $27.135,77$ & $2.713 .576,57$ \\
\hline 9 & $569.851,08$ & $542.715,31$ & $21.708,61$ & $1.628 .145,94$ \\
\hline 10 & $564.423,93$ & $542.715,31$ & $16.281,46$ & $1.085 .430,63$ \\
\hline 11 & $558.996,77$ & $542.715,31$ & $10.854,31$ & $542.715,31$ \\
\hline 12 & $553.569,62$ & $542.715,31$ & $5.427,15$ & 0,00 \\
\hline 13 & $548.142,47$ & $542.715,31$ & $195.377,51$ & \\
\hline Total & $4.537 .100,03$ & $4.341 .722,52$ & & \\
\hline
\end{tabular}

Fonte: dados da pesquisa. 
Quadro 8 - Fluxo de financiamento do ICMS estadual via Fundopem/RS

\begin{tabular}{|c|c|c|c|c|c|c|c|c|}
\hline Ano & Benefício & $\begin{array}{l}\text { Benefício } \\
\text { acumulado } \\
\text { de fruição }\end{array}$ & Prestação 1 & Prestação 2 & ... & Prestação 7 & Prestação 8 & Total de prestação \\
\hline $1^{\circ}$ & $\mathrm{R} \$ 4.131 .000,00$ & $\mathrm{R} \$ 4.131 .000,00$ & & & & & & - \\
\hline $2^{\circ}$ & $\mathrm{R} \$ 4.131 .000,00$ & $\mathrm{R} \$ 8.262 .000,00$ & & & & & & - \\
\hline $3^{\circ}$ & $R \$ 4.131 .000,00$ & $R \$ 12.393 .000,00$ & & & & & & - \\
\hline $4^{\circ}$ & $\mathrm{R} \$ 4.131 .000,00$ & $R \$ 16.524 .000,00$ & & & & & & - \\
\hline $5^{\circ}$ & $R \$ 4.131 .000,00$ & $R \$ 20.655 .000,00$ & & & & & & - \\
\hline $6^{\circ}$ & $\mathrm{R} \$ 4.131 .000,00$ & $\mathrm{R} \$ 24.786 .000,00$ & $\mathrm{R} \$ 586.132,54$ & & ... & & & $\mathrm{R} \$ 586.132,54$ \\
\hline $7^{\circ}$ & $\mathrm{R} \$ 4.131 .000,00$ & $\mathrm{R} \$ 28.917 .000,00$ & $\mathrm{R} \$ 580.705,39$ & $\mathrm{R} \$ 586.132,54$ & $\ldots$ & & & $\mathrm{R} \$ 1.166 .837,93$ \\
\hline $8^{\circ}$ & $\mathrm{R} \$ 4.131 .000,00$ & $R \$ 33.048 .000,00$ & $\mathrm{R} \$ 575.278,23$ & $\mathrm{R} \$ 580.705,39$ & & & & $\mathrm{R} \$ 1.742 .116,16$ \\
\hline $9^{\circ}$ & & & $\mathrm{R} \$ 569.851,08$ & $\mathrm{R} \$ 575.278,23$ & & & & $\mathrm{R} \$ 2.311 .967,24$ \\
\hline $10^{\circ}$ & & & $\mathrm{R} \$ 564.423,93$ & $\mathrm{R} \$ 569.851,08$ & & & & $\mathrm{R} \$ 2.876 .391,17$ \\
\hline $11^{\circ}$ & & & $\mathrm{R} \$ 558.996,77$ & $\mathrm{R} \$ 564.423,93$ & & & & $\mathrm{R} \$ 3.435 .387,94$ \\
\hline $12^{\circ}$ & & & $\mathrm{R} \$ 553.569,62$ & $\mathrm{R} \$ 558.996,77$ & & $\mathrm{R} \$ 586.132,54$ & & $\mathrm{R} \$ 3.988 .957,56$ \\
\hline $13^{\circ}$ & & & $\mathrm{R} \$ 548.142,47$ & $\mathrm{R} \$ 553.569,62$ & & $\mathrm{R} \$ 580.705,39$ & $\mathrm{R} \$ 586.132,54$ & $\mathrm{R} \$ 4.537 .100,03$ \\
\hline $14^{\circ}$ & & & & $\mathrm{R} \$ 548.142,47$ & & $\mathrm{R} \$ 575.278,23$ & $\mathrm{R} \$ 580.705,39$ & $\mathrm{R} \$ 3.950 .967,49$ \\
\hline $15^{\circ}$ & & & & & & $\mathrm{R} \$ 569.851,08$ & $\mathrm{R} \$ 575.278,23$ & $\mathrm{R} \$ 3.370 .262,10$ \\
\hline $16^{\circ}$ & & & & & & $R \$ 564.423,93$ & $\mathrm{R} \$ 569.851,08$ & $\mathrm{R} \$ 2.794 .983,87$ \\
\hline $17^{\circ}$ & & & & & & $\mathrm{R} \$ 558.996,77$ & $\mathrm{R} \$ 564.423,93$ & $\mathrm{R} \$ 2.225 .132,79$ \\
\hline $18^{\circ}$ & & & & & & $\mathrm{R} \$ 553.569,62$ & $\mathrm{R} \$ 558.996,77$ & $\mathrm{R} \$ 1.660 .708,86$ \\
\hline $19^{\circ}$ & & & & & & $\mathrm{R} \$ 548.142,47$ & $\mathrm{R} \$ 553.569,62$ & $\mathrm{R} \$ 1.101 .712,09$ \\
\hline $20^{\circ}$ & & & & & & & $\mathrm{R} \$ 548.142,47$ & $\mathrm{R} \$ 548.142,47$ \\
\hline
\end{tabular}

Fonte: dados da pesquisa.

O Quadro 8 apresenta o fluxo do financiamento do ICMS por meio do Fundopem/RS, o valor do benefício anual de $\mathrm{R} \$ 4.131 .000,00$, detalhado no Quadro 7 para o primeiro ano, e um acumulado de fruição no valor de $\mathrm{R} \$ 33.048 .000,00$. Nota-se que o valor máximo de fruição é o valor total do investimento em que a simulação corresponde a $\mathrm{R} \$ 40.000 .000,00$.

O Gráfico 1, gerado com base na projeção elaborada no Quadro 8, mostra que, até o $13^{\circ}$ ano, o valor de desembolso com o benefício sobe gradualmente até atingir o topo, momento em que todas as parcelas do benefício estão sendo pagas. 
Gráfico 1 - Efeitos do Fundopem/RS no desembolso

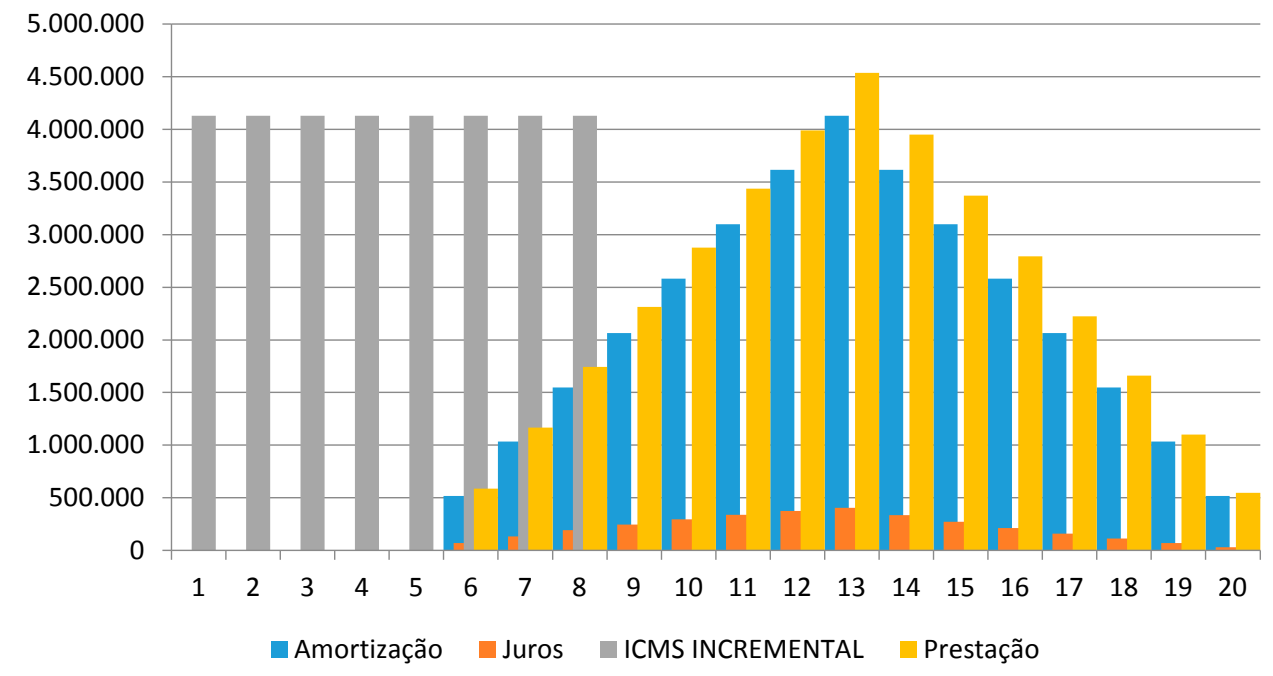

Fonte: dados da pesquisa.

Observa-se que, a partir do $14^{\circ}$ ano, o valor da prestação (amortização + juros) volta a cair em decorrência da quitação da dívida do $1^{\circ}$ ano.

Em resumo, a cooperativa troca o pagamento do ICMS incremental no período do $1^{\circ}$ ao $8^{\circ}$ ano (área retangular) pelo pagamento futuro, com desembolso crescente em um primeiro momento e decrescente a seguir, até o pagamento do ICMS relativo ao período de carência.

O Quadro 9 apresenta a utilização do Integrar/RS na amortização, dentro do sistema de amortização proposto anteriormente. Nesse caso, o valor de cada parcela de ICMS incremental anual reduz de $\mathrm{R} \$ 4.131 .000,00$ para $\mathrm{R} \$ 2.065 .500,00$. No período de carência, o saldo devedor é corrigido em 1\% ao ano; após a carência, o valor acumulado é amortizado em 8 anos. 
Quadro 9 - Amortização com Integrar/RS

\begin{tabular}{|c|c|c|c|c|}
\hline $\mathrm{T}$ & Prestação & Amortização & Juros & Saldo devedor \\
\hline 0 & & & & $2.065 .500,00$ \\
\hline 1 & & & & $2.086 .155,00$ \\
\hline 2 & & & & $2.107 .016,55$ \\
\hline 3 & & & & $2.128 .086,72$ \\
\hline 4 & & & & $2.149 .367,58$ \\
\hline 5 & & & & $2.170 .861,26$ \\
\hline 6 & $293.066,27$ & $271.357,66$ & $21.708,61$ & $1.899 .503,60$ \\
\hline 7 & $290.352,69$ & $271.357,66$ & $18.995,04$ & $1.628 .145,94$ \\
\hline 8 & $287.639,12$ & $271.357,66$ & $16.281,46$ & $1.356 .788,29$ \\
\hline 9 & $284.925,54$ & $271.357,66$ & $13.567,88$ & $1.085 .430,63$ \\
\hline 10 & $282.211,96$ & $271.357,66$ & $10.854,31$ & $814.072,97$ \\
\hline 11 & $279.498,39$ & $271.357,66$ & $8.140,73$ & $542.715,31$ \\
\hline 12 & $276.784,81$ & $271.357,66$ & $5.427,15$ & $271.357,66$ \\
\hline 13 & $274.071,23$ & $271.357,66$ & $2.713,58$ & 0,00 \\
\hline 14 & - & - & - & 0,00 \\
\hline Total & $2.268 .550,02$ & $2.170 .861,26$ & $97.688,76$ & \\
\hline
\end{tabular}

Fonte: dados da pesquisa.

Apresenta-se no Gráfico 2 a comparação de desembolso na amortização entre o Fundopem/RS e o Integrar/RS; tenta-se, dessa forma, demonstrar o impacto ocasionado pelo benefício do Integrar/RS na amortização.

Gráfico 2 - Comparação da amortização entre Fundopem/RS e Integrar/RS

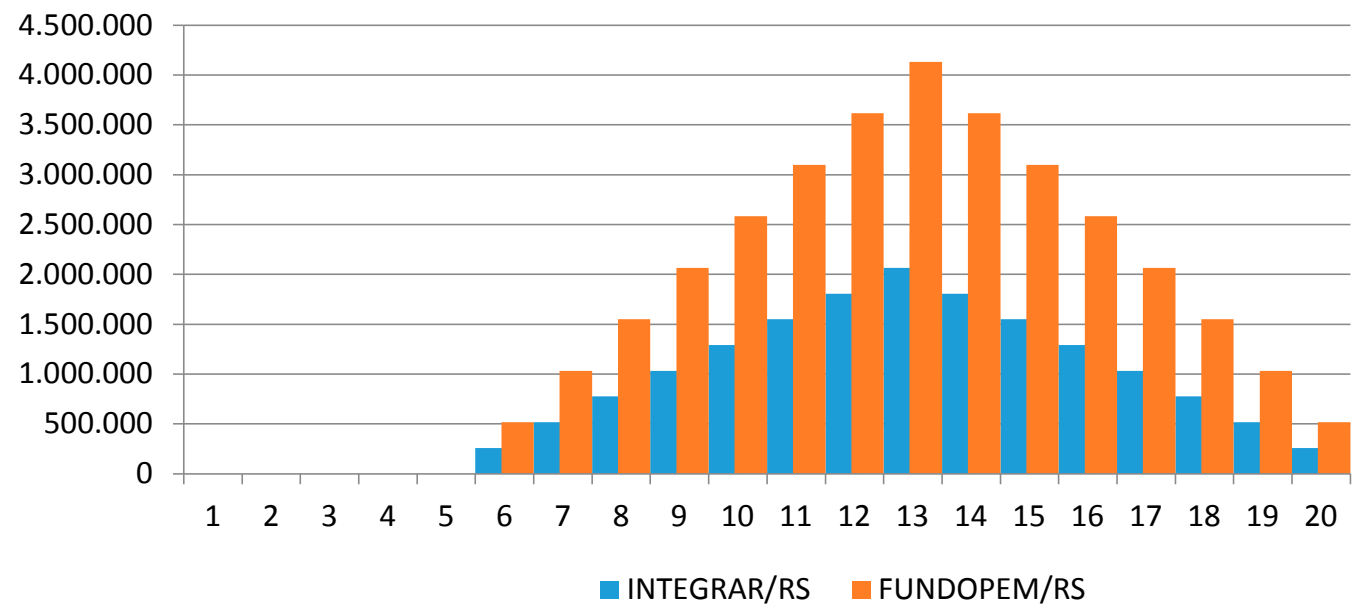

Fonte: dados da pesquisa. 
Para efeito de comparação, considerando-se o $13^{\circ}$ ano, ano em que se prevê o maior volume de desembolso, estima-se um valor de $R \$ 4.537 .100,03$, caso ocorra apenas o benefício do Fundopem/RS; quando integrado o benefício do Integrar/RS, o desembolso no mesmo período cai para $\mathrm{R} \$ 2.065 .500,00$.

\section{Descrição econômico-financeira da agroindústria com o benefício do Fundopem/RS}

Nesta seção, pretende-se apresentar o incremento econômico-financeiro gerado pelo Fundopem/RS ao projeto de expansão da cooperativa, com previsão de investimento de $\mathrm{R} \$ 40.000 .000,00$.

Após o enquadramento no Fundopem/RS, descrito anteriormente, e a obtenção de 80 pontos, a empresa teria ainda o direito de financiar 75\% do ICMS incremental gerado no projeto, com prazo de financiamento de 8 anos na fruição, carência de 5 anos, amortização de 8 anos e juros de $1 \%$ ao ano.

Ressalvasse que, para melhor compreensão de valores e do benefício, foram utilizados valores anuais, sendo que, na prática, o financiamento é concedido à empresa mês a mês, até atingir o prazo máximo de fruição, neste caso 96 meses, ou $100 \%$ do investimento fixo realizado, neste caso $\mathrm{R} \$ 40.000 .000,00$.

O Quadro 10 apresenta o fluxo de caixa anual projetado com incentivo governamental do Fundopem/RS. Observa-se que, nos primeiros oito anos do fluxo de caixa, a cooperativa pagaria apenas 25\% do ICMS incremental devido (os $75 \%$ restantes seriam financiados): $R \$ 1.377 .000,00(\mathrm{R} \$ 5.508 .000,00 * 25 \%)$. Nota-se que, só com o fim da carência de 5 anos, é efetuado o primeiro pagamento do ICMS diferido. Com o incentivo governamental, o fluxo de caixa líquido estimado seria de $\mathrm{R} \$ 220.591 .199,76$.

Como o efeito do Fundopem/RS para as empresas consiste, basicamente, em aliviar o seu fluxo de caixa no início da operação, postergando parte das despesas com impostos para o futuro, é pertinente compreender as condições do programa como uma forma de captação de capital de giro. 
Quadro 10 - Fluxo de caixa estimado do projeto de agroindústria com Fundopem/RS

\begin{tabular}{|c|c|c|c|c|c|c|c|c|c|}
\hline Ano & Investimento & Receita & $\begin{array}{c}\text { - ICMS incremental } \\
\text { a pagar }\end{array}$ & - ICMS diferido & $-\mathrm{CPV}$ & Lucro bruto & $\begin{array}{l}\text { - Despesas } \\
\text { operacionais sem } \\
\text { depreciação }\end{array}$ & $\begin{array}{l}\text { Fluxo de caixa } \\
\text { bruto }\end{array}$ & $\begin{array}{l}\text { Fluxo de caixa } \\
\text { liquido }\end{array}$ \\
\hline ano 0 & - $\mathrm{R} \$ 40.000 .000,00$ & & & & & & & & $-\mathrm{R} \$ 40.000 .000,00$ \\
\hline ano 1 & & $\mathrm{R} \$ 45.900 .000,00$ & - $\mathrm{R} \$ 1.377 .000,00$ & $-R \$-$ & $-\mathrm{R} \$ 18.000 .000,00$ & $\mathrm{R} \$ 27.900 .000,00$ & - $R \$ 7.200 .000,00$ & $\mathrm{R} \$ 19.323 .000,00$ & $\mathrm{R} \$ 19.323 .000,00$ \\
\hline ano 2 & & $\mathrm{R} \$ 45.900 .000,00$ & - $\mathrm{R} \$ 1.377 .000,00$ & $-R \$-$ & $-\mathrm{R} \$ 18.000 .000,00$ & $\mathrm{R} \$ 27.900 .000,00$ & - $R \$ 7.200 .000,00$ & $\mathrm{R} \$ 19.323 .000,00$ & $\mathrm{R} \$ 19.323 .000,00$ \\
\hline ano 3 & & $\mathrm{R} \$ 45.900 .000,00$ & - R\$ $1.377 .000,00$ & $-R \$-$ & $-R \$ 18.000 .000,00$ & $\mathrm{R} \$ 27.900 .000,00$ & - $\operatorname{R\$ 7.200.000,00}$ & $\mathrm{R} \$ 19.323 .000,00$ & $\mathrm{R} \$ 19.323 .000,00$ \\
\hline ano 4 & & $\mathrm{R} \$ 45.900 .000,00$ & - $R \$ 1.377 .000,00$ & $-R \$-$ & $-\mathrm{R} \$ 18.000 .000,00$ & $\mathrm{R} \$ 27.900 .000,00$ & - $\mathrm{R} \$ 7.200 .000,00$ & $\mathrm{R} \$ 19.323 .000,00$ & $\mathrm{R} \$ 19.323 .000,00$ \\
\hline ano 5 & & $\mathrm{R} \$ 45.900 .000,00$ & - $R \$ 1.377 .000,00$ & $-R \$-$ & - $\mathrm{R} \$ 18.000 .000,00$ & $\mathrm{R} \$ 27.900 .000,00$ & - $\mathrm{R} \$ 7.200 .000,00$ & $\mathrm{R} \$ 19.323 .000,00$ & $\mathrm{R} \$ 19.323 .000,00$ \\
\hline ano 6 & & $\mathrm{R} \$ 45.900 .000,00$ & - $\mathrm{R} \$ 1.377 .000,00$ & - $R \$ 586.132,54$ & $-R \$ 18.000 .000,00$ & $\mathrm{R} \$ 27.313 .867,46$ & - $R \$ 7.200 .000,00$ & $\mathrm{R} \$ 18.736 .867,46$ & $\mathrm{R} \$ 18.736 .867,46$ \\
\hline ano 7 & & $\mathrm{R} \$ 45.900 .000,00$ & $-\mathrm{R} \$ 1.377 .000,00$ & $-\mathrm{R} \$ 1.166 .837,93$ & $-\mathrm{R} \$ 18.000 .000,00$ & $\mathrm{R} \$ 26.733 .162,07$ & - $R \$ 7.200 .000,00$ & $\mathrm{R} \$ 18.156 .162,07$ & $\mathrm{R} \$ 18.156 .162,07$ \\
\hline ano 8 & & $\mathrm{R} \$ 45.900 .000,00$ & - $\mathrm{R} \$ 1.377 .000,00$ & - $\mathrm{R} \$ 1.742 .116,16$ & - $\mathrm{R} \$ 18.000 .000,00$ & $\mathrm{R} \$ 26.157 .883,84$ & - $R \$ 7.200 .000,00$ & $\mathrm{R} \$ 17.580 .883,84$ & $\mathrm{R} \$ 17.580 .883,84$ \\
\hline ano 9 & & $\mathrm{R} \$ 45.900 .000,00$ & - $R \$ 5.508 .000,00$ & - R\$2.311.967,24 & - $\mathrm{R} \$ 18.000 .000,00$ & $\mathrm{R} \$ 25.588 .032,76$ & - $\mathrm{R} \$ 7.200 .000,00$ & $\mathrm{R} \$ 12.880 .032,76$ & $\mathrm{R} \$ 12.880 .032,76$ \\
\hline ano 10 & - $\mathrm{R} \$ 40.000 .000,00$ & $\mathrm{R} \$ 45.900 .000,00$ & - R\$ 5.508.000,00 & - R\$2.876.391,17 & - $R \$ 18.000 .000,00$ & $\mathrm{R} \$ 25.023 .608,83$ & - R\$ 7.200.000,00 & $\mathrm{R} \$ 12.315 .608,83$ & - R\$ 27.684.391,17 \\
\hline ano 11 & & $\mathrm{R} \$ 45.900 .000,00$ & $-\mathrm{R} \$ 5.508 .000,00$ & - $\mathrm{R} \$ 3.435 .387,94$ & $-\mathrm{R} \$ 18.000 .000,00$ & $\mathrm{R} \$ 24.464 .612,06$ & - $R \$ 7.200 .000,00$ & $\mathrm{R} \$ 11.756 .612,06$ & $\mathrm{R} \$ 11.756 .612,06$ \\
\hline ano 12 & & $\mathrm{R} \$ 45.900 .000,00$ & - $\mathrm{R} \$ 5.508 .000,00$ & - $R \$ 3.988 .957,56$ & $-\mathrm{R} \$ 18.000 .000,00$ & $\mathrm{R} \$ 23.911 .042,44$ & - R\$7.200.000,00 & $\mathrm{R} \$ 11.203 .042,44$ & $\mathrm{R} \$ 11.203 .042,44$ \\
\hline ano 13 & & $\mathrm{R} \$ 45.900 .000,00$ & $-\mathrm{R} \$ 5.508 .000,00$ & $-\mathrm{R} \$ 4.537 .100,03$ & $-\mathrm{R} \$ 18.000 .000,00$ & $\mathrm{R} \$ 23.362 .899,97$ & - $R \$ 7.200 .000,00$ & $\mathrm{R} \$ 10.654 .899,97$ & $\mathrm{R} \$ 10.654 .899,97$ \\
\hline ano 14 & & $\mathrm{R} \$ 45.900 .000,00$ & - $R \$ 5.508 .000,00$ & - R\$ 3.950.967,49 & $-\mathrm{R} \$ 18.000 .000,00$ & $\mathrm{R} \$ 23.949 .032,51$ & - R\$ 7.200.000,00 & R\$ 11.241.032,51 & $\mathrm{R} \$ 11.241 .032,51$ \\
\hline ano 15 & & $\mathrm{R} \$ 45.900 .000,00$ & $-R \$ 5.508 .000,00$ & - $R \$ 3.370 .262,10$ & $-\mathrm{R} \$ 18.000 .000,00$ & $\mathrm{R} \$ 24.529 .737,90$ & - $R \$ 7.200 .000,00$ & R\$ $11.821 .737,90$ & $\mathrm{R} \$ 11.821 .737,90$ \\
\hline ano 16 & & $\mathrm{R} \$ 45.900 .000,00$ & - $R \$ 5.508 .000,00$ & - $R \$ 2.794 .983,87$ & $-\mathrm{R} \$ 18.000 .000,00$ & $\mathrm{R} \$ 25.105 .016,13$ & - $R \$ 7.200 .000,00$ & $\mathrm{R} \$ 12.397 .016,13$ & $\mathrm{R} \$ 12.397 .016,13$ \\
\hline ano 17 & & $\mathrm{R} \$ 45.900 .000,00$ & $-\mathrm{R} \$ 5.508 .000,00$ & $-\mathrm{R} \$ 2.225 .132,79$ & $-\mathrm{R} \$ 18.000 .000,00$ & $\mathrm{R} \$ 25.674 .867,21$ & - $R \$ 7.200 .000,00$ & $\mathrm{R} \$ 12.966 .867,21$ & $\mathrm{R} \$ 12.966 .867,21$ \\
\hline ano 18 & & $\mathrm{R} \$ 45.900 .000,00$ & - R\$ 5.508.000,00 & - R\$ $1.660 .708,86$ & $-\mathrm{R} \$ 18.000 .000,00$ & $\mathrm{R} \$ 26.239 .291,14$ & - $\mathrm{R} \$ 7.200 .000,00$ & $\mathrm{R} \$ 13.531 .291,14$ & $\mathrm{R} \$ 13.531 .291,14$ \\
\hline ano 19 & & $\mathrm{R} \$ 45.900 .000,00$ & - $R \$ 5.508 .000,00$ & - $R \$ 1.101 .712,09$ & $-\mathrm{R} \$ 18.000 .000,00$ & $\mathrm{R} \$ 26.798 .287,91$ & - $R \$ 7.200 .000,00$ & $\mathrm{R} \$ 14.090 .287,91$ & $\mathrm{R} \$ 14.090 .287,91$ \\
\hline ano 20 & & $\mathrm{R} \$ 45.900 .000,00$ & - $R \$ 5.508 .000,00$ & - $\mathrm{R} \$ 548.142,47$ & $-\mathrm{R} \$ 18.000 .000,00$ & $\mathrm{R} \$ 27.351 .857,53$ & - $\mathrm{R} \$ 7.200 .000,00$ & $\mathrm{R} \$ 14.643 .857,53$ & $\mathrm{R} \$ 14.643 .857,53$ \\
\hline Total & - $R \$ 80.000 .000,00$ & $R \$ 918.000 .000,00$ & $-\mathrm{R} \$ 77.112 .000,00$ & $-\mathrm{R} \$ 36.296 .800,24$ & $-\mathrm{R} \$ 360.000 .000,00$ & $\mathrm{R} \$ 521.703 .199,76$ & $-R \$ 144.000 .000,00$ & $\mathrm{R} \$ 300.591 .199,76$ & $\mathrm{R} \$ 220.591 .199,76$ \\
\hline
\end{tabular}

Fonte: dados da pesquisa.

O Quadro 11 apresenta os indicadores utilizados para medir a viabilidade econômica do projeto. Para cálculo do VPL, utilizou-se um CO de 8\%; com isso, estima-se um VPL no valor de $\mathrm{R} \$ 100.549 .607,61$. A TIR do projeto está avaliada em $46,13 \%$.

Quadro 11 - Indicadores de viabilidade da agroindústria com incentivo do Fundopem/RS

\begin{tabular}{|c|c|}
\hline VPL & $\mathrm{R} \$ 100.549 .607,61$ \\
\hline TIR & $46,13 \%$ \\
\hline CO & $8,0 \%$ \\
\hline
\end{tabular}

Fonte: dados da pesquisa.

Para efeitos de comparação, os Gráficos 3 e 4 apresentam a alavancagem proporcionada pelo Fundopem/RS em relação ao projeto sem benefício.

O Gráfico 3 compara o VPL sem e com benefício fiscal, e observa-se uma alavancagem de $R \$ 9.920 .051,71$ entre os dois cenários. 
Gráfico 3 - Comparação do VPL sem benefício e com Fundopem/RS

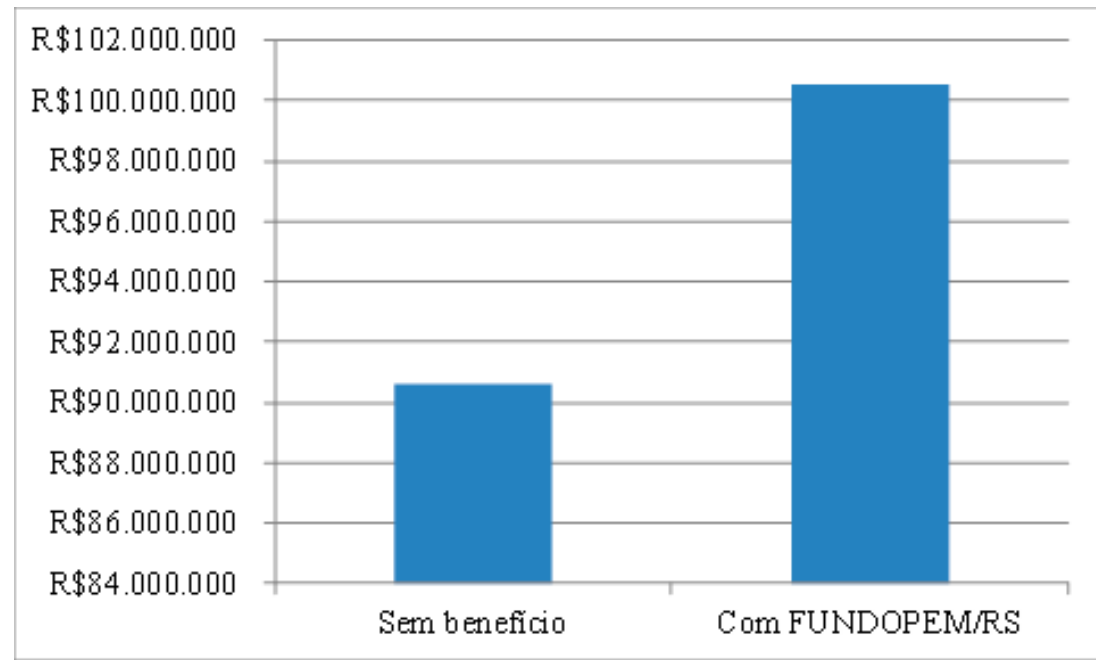

Fonte: dados da pesquisa.

O Gráfico 4 mostra a alavancagem proporcionada pelo Fundopem/RS na TIR do projeto de investimento da cooperativa. Estima-se um impulso de 9,87\% na TIR, em comparação ao projeto de investimento sem benefício.

Gráfico 4 - Comparação da TIR sem benefício e com Fundopem/RS

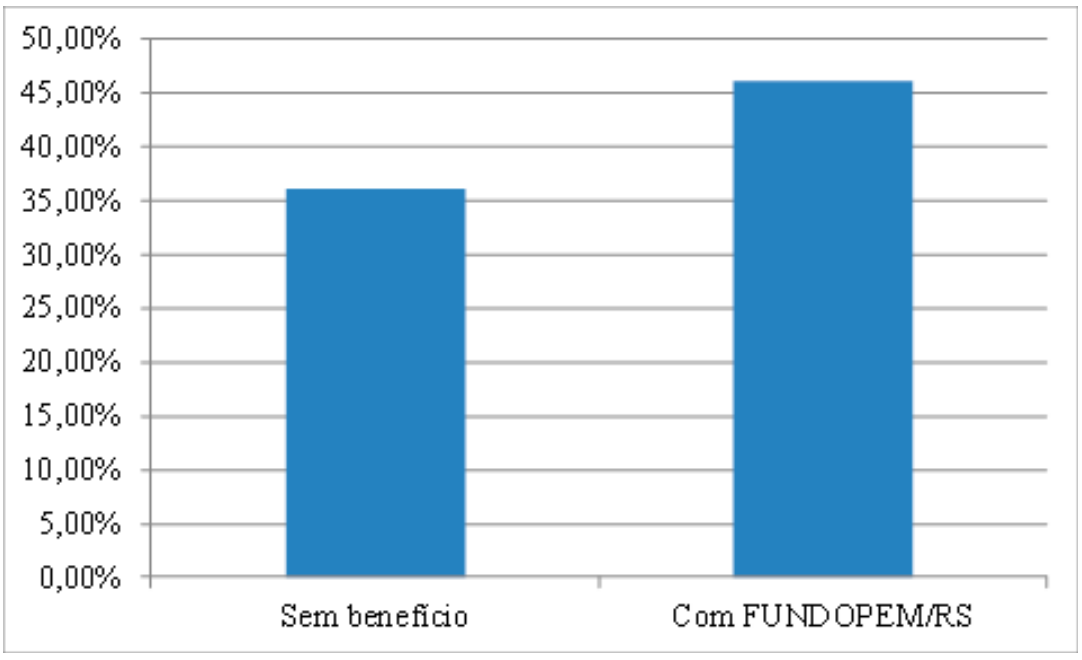

Fonte: dados da pesquisa. 


\section{Descrição econômico-financeira da agroindústria com o benefício Integrar/RS}

Nesta seção, pretende-se apresentar o incremento econômico-financeiro gerado pelo Integrar/RS ao projeto de expansão. Após o enquadramento no Fundopem/ RS, já descrito anteriormente, a empresa é enquadrada no Integrar/RS.

O Integrar/RS consiste em um incentivo adicional ao Fundopem/RS. Como abatimento na forma de percentual, incide sobre cada parcela da prestação, o que inclui valor da amortização acrescido aos encargos da operação. Como mencionado, o percentual de enquadramento utilizado na simulação do projeto da cooperativa é de $50 \%$.

O Quadro 12 apresenta o fluxo de caixa anual do projeto com os benefícios do Fundopem/RS e do Integrar/RS.

Estima-se que o total de ICMS diferido com desconto do Integrar/RS chega, no final do fluxo de caixa, ao valor de $\mathrm{R} \$ 18.148 .400,12$. Com o acréscimo do benefício Integrar/RS, o fluxo de caixa líquido estimado seria de $\mathrm{R} \$ 238.729 .599,88$.

Quadro 12 - Fluxo de caixa estimado do projeto de agroindústria com Fundopem/RS e Integrar/RS

\begin{tabular}{|c|c|c|c|c|c|c|c|c|c|}
\hline Ano & Investimento & Receita & $\begin{array}{l}\text { ICMS incremental } \\
\text { a pagar }\end{array}$ & $\begin{array}{l}\text { ICMS diferido com } \\
\text { desconto Integrar/RS }\end{array}$ & CPV & Lucro bruto & $\begin{array}{c}\text { Despesas operacionais } \\
\text { sem depreciação }\end{array}$ & Fluxo de caixa bruto & Fluxo de caixa liquido \\
\hline ano 0 & $-\mathrm{R} \$ 40.000 .000,00$ & & & & & & & & $-\mathrm{R} \$ 40.000 .000,00$ \\
\hline ano 1 & & $\mathrm{R} \$ 45.900 .000,00$ & - R\$ $1.377 .000,00$ & -RS - & - $\mathrm{R} \$ 18.000 .000,00$ & $\mathrm{R} \$ 27.900 .000,00$ & - $\mathrm{R} \$ 7.200 .000,00$ & $\mathrm{R} \$ 19.323 .000,00$ & $\mathrm{R} \$ 19.323 .000,00$ \\
\hline ano 2 & & $\mathrm{R} \$ 45.900 .000,00$ & - $R \$ 1.377 .000,00$ & $-R S-$ & - $R \$ 18.000 .000,00$ & $\mathrm{R} \$ 27.900 .000,00$ & - $\mathrm{R} \$ 7.200 .000,00$ & $\mathrm{R} \$ 19.323 .000,00$ & $\mathrm{R} \$ 19.323 .000,00$ \\
\hline ano 3 & & $\mathrm{R} \$ 45.900 .000,00$ & - R\$ $1.377 .000,00$ & -RS - & - $\mathrm{R} \$ 18.000 .000,00$ & $\mathrm{R} \$ 27.900 .000,00$ & - $\mathrm{R} \$ 7.200 .000,00$ & R\$ $19.323 .000,00$ & $\mathrm{R} \$ 19.323 .000,00$ \\
\hline ano 4 & & $\mathrm{R} \$ 45.900 .000,00$ & - $R \$ 1.377 .000,00$ & $-\mathrm{RS}-$ & - $R \$ 18.000 .000,00$ & $\mathrm{R} \$ 27.900 .000,00$ & - $R \$ 7.200 .000,00$ & $\mathrm{R} \$ 19.323 .000,00$ & $\mathrm{R} \$ 19.323 .000,00$ \\
\hline ano 5 & & $\mathrm{R} \$ 45.900 .000,00$ & - $R \$ 1.377 .000,00$ & - RS - & - $R \$ 18.000 .000,00$ & $\mathrm{R} \$ 27.900 .000,00$ & - $\mathrm{R} \$ 7.200 .000,00$ & $\mathrm{R} \$ 19.323 .000,00$ & $\mathrm{R} \$ 19.323 .000,00$ \\
\hline ano 6 & & $\mathrm{R} \$ 45.900 .000,00$ & $-\mathrm{R} \$ 1.377 .000,00$ & - $R \$ 293.066,27$ & - $\mathrm{R} \$ 18.000 .000,00$ & $\mathrm{R} \$ 27.606 .933,73$ & - $\mathrm{R} \$ 7.200 .000,00$ & $\mathrm{R} \$ 19.029 .933,73$ & $\mathrm{R} \$ 19.029 .933,73$ \\
\hline ano 7 & & $\mathrm{R} \$ 45.900 .000,00$ & - $R \$ 1.377 .000,00$ & - $R \$ 583.418,96$ & - $R \$ 18.000 .000,00$ & $\mathrm{R} \$ 27.316 .581,04$ & - R\$ 7.200.000,00 & $\mathrm{R} \$ 18.739 .581,04$ & $\mathrm{R} \$ 18.739 .581,04$ \\
\hline ano 8 & & $\mathrm{R} \$ 45.900 .000,00$ & - $R \$ 1.377 .000,00$ & - $R \$ 871.058,08$ & - R\$ $18.000 .000,00$ & $\mathrm{R} \$ 27.028 .941,92$ & $-\mathrm{R} \$ 7.200 .000,00$ & $\operatorname{R} \$ 18.451 .941,92$ & $\mathrm{R} \$ 18.451 .941,92$ \\
\hline ano 9 & & $\mathrm{R} \$ 45.900 .000,00$ & - $R \$ 5.508 .000,00$ & - $\mathrm{R} \$ 1.155 .983,62$ & - R\$ $18.000 .000,00$ & $\mathrm{R} \$ 26.744 .016,38$ & $-\mathrm{R} \$ 7.200 .000,00$ & $\mathrm{R} \$ 14.036 .016,38$ & $\mathrm{R} \$ 14.036 .016,38$ \\
\hline ano 10 & $-\mathrm{R} \$ 40.000 .000,00$ & $\mathrm{R} \$ 45.900 .000,00$ & - $R \$ 5.508 .000,00$ & $-\mathrm{R} \$ 1.438 .195,58$ & - $\mathrm{R} \$ 18.000 .000,00$ & $\mathrm{R} \$ 26.461 .804,42$ & - $\mathrm{R} \$ 7.200 .000,00$ & $\mathrm{R} \$ 13.753 .804,42$ & - $\mathrm{R} \$ 26.246 .195,58$ \\
\hline ano 11 & & $\mathrm{R} \$ 45.900 .000,00$ & - $R \$ 5.508 .000,00$ & - $\mathrm{R} \$ 1.717 .693,97$ & $-\mathrm{R} \$ 18.000 .000,00$ & $\mathrm{R} \$ 26.182 .306,03$ & - $\mathrm{R} \$ 7.200 .000,00$ & $\mathrm{R} \$ 13.474 .306,03$ & $\mathrm{R} \$ 13.474 .306,03$ \\
\hline ano 12 & & $\mathrm{R} \$ 45.900 .000,00$ & - $R \$ 5.508 .000,00$ & - R\$ 1.994.478,78 & - $\mathrm{R} \$ 18.000 .000,00$ & $\mathrm{R} \$ 25.905 .521,22$ & - $\mathrm{R} \$ 7.200 .000,00$ & $\mathrm{R} \$ 13.197 .521,22$ & $\mathrm{R} \$ 13.197 .521,22$ \\
\hline ano 13 & & $\mathrm{R} \$ 45.900 .000,00$ & - $R \$ 5.508 .000,00$ & $-R \$ 2.268 .550,02$ & - $R \$ 18.000 .000,00$ & $\mathrm{R} \$ 25.631 .449,98$ & - $R \$ 7.200 .000,00$ & $\mathrm{R} \$ 12.923 .449,98$ & $\mathrm{R} \$ 12.923 .449,98$ \\
\hline ano 14 & & $\mathrm{R} \$ 45.900 .000,00$ & - $R \$ 5.508 .000,00$ & - $\mathrm{R} \$ 1.975 .483,75$ & - $R \$ 18.000 .000,00$ & $\mathrm{R} \$ 25.924 .516,25$ & - $\mathrm{R} \$ 7.200 .000,00$ & $\mathrm{R} \$ 13.216 .516,25$ & $\mathrm{R} \$ 13.216 .516,25$ \\
\hline ano 15 & & $\mathrm{R} \$ 45.900 .000,00$ & - $R \$ 5.508 .000,00$ & $-R \$ 1.685 .131,05$ & - $R \$ 18.000 .000,00$ & $\mathrm{R} \$ 26.214 .868,95$ & - R\$ 7.200.000,00 & R\$ 13.506.868,95 & $\mathrm{R} \$ 13.506 .868,95$ \\
\hline ano 16 & & $\mathrm{R} \$ 45.900 .000,00$ & - $R \$ 5.508 .000,00$ & - R\$1.397.491,94 & - $R \$ 18.000 .000,00$ & $\mathrm{R} \$ 26.502 .508,06$ & - $\mathrm{R} \$ 7.200 .000,00$ & $\mathrm{R} \$ 13.794 .508,06$ & $\mathrm{R} \$ 13.794 .508,06$ \\
\hline ano 17 & & $\mathrm{R} \$ 45.900 .000,00$ & $-\mathrm{R} \$ 5.508 .000,00$ & - R\$ 1.112.566,39 & - $R \$ 18.000 .000,00$ & $\mathrm{R} \$ 26.787 .433,61$ & - $\mathrm{R} \$ 7.200 .000,00$ & $\mathrm{R} \$ 14.079 .433,61$ & $\mathrm{R} \$ 14.079 .433,61$ \\
\hline ano 18 & & $\mathrm{R} \$ 45.900 .000,00$ & - $R \$ 5.508 .000,00$ & - $R \$ 830.354,43$ & - $R \$ 18.000 .000,00$ & $\mathrm{R} \$ 27.069 .645,57$ & - R\$ 7.200.000,00 & R\$ $14.361 .645,57$ & $\mathrm{R} \$ 14.361 .645,57$ \\
\hline ano 19 & & $\mathrm{R} \$ 45.900 .000,00$ & - $R \$ 5.508 .000,00$ & $-R \$ 550.856,04$ & - $R \$ 18.000 .000,00$ & $\mathrm{R} \$ 27.349 .143,96$ & - $R \$ 7.200 .000,00$ & $\mathrm{R} \$ 14.641 .143,96$ & $\mathrm{R} \$ 14.641 .143,96$ \\
\hline ano 20 & & $\mathrm{R} \$ 45.900 .000,00$ & - $R \$ 5.508 .000,00$ & - $R \$ 274.071,23$ & - $R \$ 18.000 .000,00$ & $\mathrm{R} \$ 27.625 .928,77$ & - $\mathrm{R} \$ 7.200 .000,00$ & $\mathrm{R} \$ 14.917 .928,77$ & $\mathrm{R} \$ 14.917 .928,77$ \\
\hline Total & - $R \$ 80.000 .000,00$ & $\mathrm{R} \$ 918.000 .000,00$ & - $R \$ 77.112 .000,00$ & - $R \$ 18.148 .400,12$ & - $R \$ 360.000 .000,00$ & $\mathrm{R} \$ 539.851 .599,88$ & - $\mathrm{R} \$ 144.000 .000,00$ & $\mathrm{R} \$ 318.739 .599,88$ & $\mathrm{R} \$ 238.739 .599,88$ \\
\hline
\end{tabular}

Fonte: dados da empresa. 
O Quadro 13 apresenta os indicadores utilizados para medir a viabilidade econômica do projeto. Para cálculo da VPL, utilizou-se um CO de 8\%; com isso, estima-se um VPL no valor de $\mathrm{R} \$ 107.459 .264,49$. A TIR do projeto está avaliada em $46,47 \%$.

Quadro 13 - Indicadores de viabilidade da agroindústria com incentivo do Integrar/RS

\begin{tabular}{|c|c|}
\hline VPL & $\mathrm{R} \$ 107.459 .264,49$ \\
\hline TIR & $46,47 \%$ \\
\hline CO & $8 \%$ \\
\hline
\end{tabular}

Fonte: dados da pesquisa.

\section{Comparações dos cenários projetados com e sem incentivo governamental}

Nesta seção, pretende-se comparar os três cenários projetados, sem incentivo, com incentivo do Fundopem/RS e com incentivo do Fundopem/RS e do Integrar/ RS, possibilitando verificar as diferenças entre seus fluxos de custos e benefícios.

Quadro 14 - Comparação dos cenários projetados

\begin{tabular}{|c|c|c|c|}
\hline & $1^{\circ}$ - Sem benefício & $2^{\circ}$ - Com Fundopem/RS & $\begin{array}{c}3^{\circ} \text { - Com Fundopem/RS } \\
\text { e Integrar/RS }\end{array}$ \\
\hline Investimento e reinvestimento & - $\mathrm{R} \$ 80.000 .000,00$ & - $R \$ 80.000 .000,00$ & - $R \$ 80.000 .000,00$ \\
\hline Receita & $\mathrm{R} \$ 918.000 .000,00$ & $\mathrm{R} \$ 918.000 .000,00$ & $\mathrm{R} \$ 918.000 .000,00$ \\
\hline (-) ICMS incremental a pagar & $\mathrm{R} \$ 110.160 .000,00$ & $\mathrm{R} \$ 77.112 .000,00$ & $\mathrm{R} \$ 77.112 .000,00$ \\
\hline (-) ICMS diferido & $\mathrm{R} \$-$ & $\mathrm{R} \$ 36.296 .800,24$ & $\mathrm{R} \$ 18.148 .400,12$ \\
\hline$(-) \mathrm{CPV}$ & $\mathrm{R} \$ 360.000 .000,00$ & $\mathrm{R} \$ 360.000 .000,00$ & $\mathrm{R} \$ 360.000 .000,00$ \\
\hline Lucro bruto & $\mathrm{R} \$ 447.840 .000,00$ & $\mathrm{R} \$ 521.703 .199,76$ & $\mathrm{R} \$ 539.851 .599,88$ \\
\hline $\begin{array}{l}\text { Despesas operacionais sem } \\
\text { depreciação }\end{array}$ & $\mathrm{R} \$ 144.000 .000,00$ & $\mathrm{R} \$ 144.000 .000,00$ & $\mathrm{R} \$ 144.000 .000,00$ \\
\hline $\begin{array}{l}\text { Saldo do fluxo de caixa bruto (de } \\
1 \text { a 20) }\end{array}$ & $\mathrm{R} \$ 303.840 .000,00$ & $\mathrm{R} \$ 300.591 .199,76$ & $\mathrm{R} \$ 318.739 .599,88$ \\
\hline $\begin{array}{l}\text { Saldo do fluxo de caixa líquido (de } \\
0 \text { a 20) }\end{array}$ & $\mathrm{R} \$ 223.840 .000,00$ & $\mathrm{R} \$ 220.591 .199,76$ & $R \$ 238.739 .599,88$ \\
\hline VPL & $\mathrm{R} \$ 90.629 .555,89$ & $\mathrm{R} \$ 100.549 .607,61$ & $\mathrm{R} \$ 107.459 .264,49$ \\
\hline TIR & $36,26 \%$ & $46,13 \%$ & $46,47 \%$ \\
\hline $\mathrm{CO}$ & $8 \%$ & $8 \%$ & $8 \%$ \\
\hline
\end{tabular}

Fonte: dados da pesquisa. 
No Quadro 14, observa-se, na linha do ICMS incremental a pagar, uma diminuição de $\mathrm{R} \$ 33.048 .000,00$ do valor pago nos $2^{\circ}$ e $3^{\circ}$ cenários, comparado ao valor a ser pago no $1^{\circ}$ cenário. Essa diferença corresponde ao valor total do benefício acumulado, sem juros, no período de fruição de 8 anos. Na linha seguinte, verifica-se que o valor estimado do ICMS diferido para o $2^{\circ}$ cenário é de $R \$ 36.296 .800,24$, com juros, sendo que, se for aplicado o desconto percentual de $50 \%$ concedido para o Integrar/RS, o valor chega a R $\$ 18.148 .400,12$.

Outra importante comparação entre os cenários apresentados é o lucro bruto; estima-se que, devido ao impacto ocasionado com o Fundopem/RS, o lucro bruto aumente, do $1^{\circ}$ para o $2^{\circ}$ cenário, para $\mathrm{R} \$ 73.863199,70$ e, do $1^{\circ}$ para o $3^{\circ}$, para $\mathrm{R} \$$ $92.011 .599,80$, contabilizando um aumento no lucro bruto de $20,55 \%$.

Em relação ao saldo do fluxo de caixa bruto, observado nos Quadros 5, 10 e 12 e resumido no Quadro 14, verificou-se uma queda de $R \$ 3.248 .800,30$ (1,07\%) na comparação do cenário sem incentivos fiscais com o cenário com incentivo do Fundopem/RS. Essa perda é revertida no cenário de incentivo com o Integrar/RS, em comparação com o cenário sem incentivo, pois há um aumento no fluxo de caixa bruto de $\mathrm{R} \$ 14.899 .599,80$ (4,90\%). Essa mesma situação ocorre em relação ao saldo final do fluxo de caixa líquido, em que há uma redução de $\mathrm{R} \$ 3.248 .800,30$ $(1,45 \%)$, do $1^{\circ}$ para o $2^{\circ}$ cenário, e um aumento de $\mathrm{R} \$ 14.899 .599,80(6,65 \%)$ no $3^{\circ}$ cenário.

O Gráfico 5 apresenta a comparação entre o projeto sem incentivo e o com incentivo do Fundopem/RS e do Integrar/RS, com relação aos indicadores econômicos TIR e VPL.

Gráfico 5 - Comparação entre TIR e VPL dos três cenários
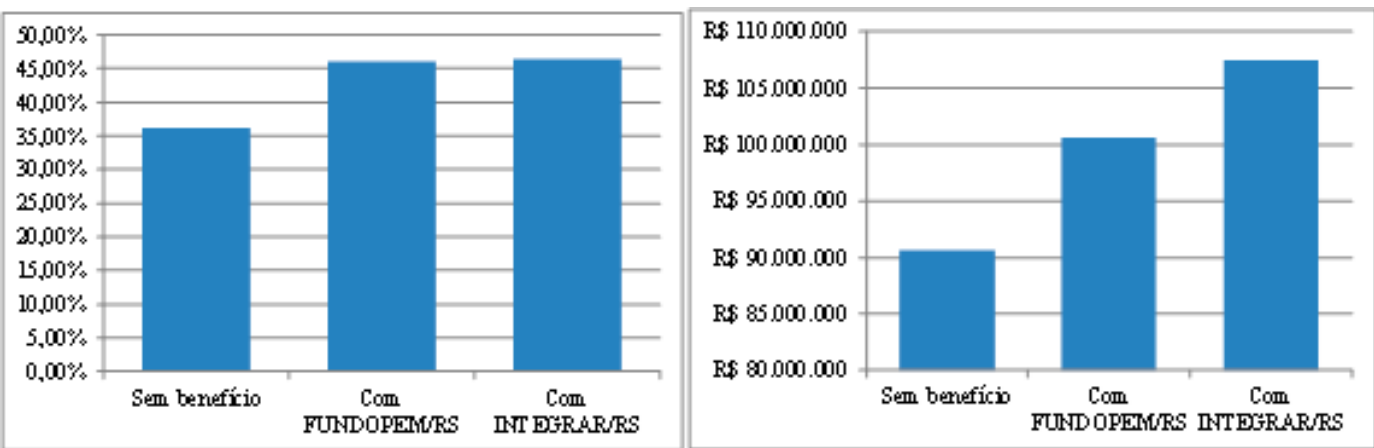

Fonte: dados da pesquisa. 
Analisando a TIR do fluxo de caixa sem o incentivo, verifica-se que a rentabilidade anual seria de $36,26 \%$; com Fundopem/RS, a TIR aumenta em 9,87 pontos percentuais (46,13\%); e com Integrar/RS, há um aumento de mais de 0,34 pontos percentuais $(46,47 \%)$. Ou seja, não há um impacto significativo da TIR entre os dois tipos de incentivos.

Ao analisar o VPL, verifica-se que, no cenário sem incentivo, há a criação de uma riqueza de $\mathrm{R} \$ 90.629 .555,89$, sendo que o incentivo do Fundopem/RS alavancaria esse valor para $R \$ 100.549 .607,61$, um aumento de $10,94 \%$. Haveria um aumento da riqueza criada para os sócios da cooperativa por meio do Integrar/RS de $\mathrm{R} \$ 107.459 .264,49$. Observando o VPL, haveria uma diferença de riqueza criada entre os dois tipos de incentivos fiscais de $\mathrm{R} \$ 6.909 .656,88$, valor significativo, se comprado ao valor do investimento inicial.

Assim, a comparação dos resultados permite medir a importância dos benefícios oferecidos no estado do Rio Grande do Sul, melhorando os indicadores de viabilidade do projeto e viabilizando verificar as dinâmicas sem e com incentivos fiscais no fluxo de caixa do projeto. No entanto, verifica-se que os incentivos fiscais proporcionados pelo governo não devem ser o fator decisivo para a realização do investimento pela empresa, pois o projeto apresenta viabilidade econômica para a sua implementação. Ambos os benefícios, Fundopem/RS e Integrar/RS, permitem que a empresa tenha um alívio nas saídas de caixa dos anos iniciais do projeto, diminuindo o risco de geração de caixa, e ainda possibilitam alavancar os indicadores econômicos, aumentando, com isso, a lucratividade e a viabilidade do investimento.

\section{Conclusão}

O estudo apresentado permite afirmar que o Fundopem/RS age como um postergador de imposto, sendo um incentivo na geração de capital de giro para a empresa no momento do investimento, seja ele de ampliação ou de instalação. Para a concessão do benefício, além do investimento, a empresa precisa atingir a pontuação mínima estabelecida pelos sete critérios, a fim de definir os prazos de investimento. O Integrar/RS consiste em abater, na forma de percentual, a prestação a ser paga pelo financiamento gerado com o Fundopem/RS, subsidiando a relação entre o governo do estado e a indústria.

Na pesquisa realizada com os diretores da cooperativa em questão, foi possível simular um enquadramento e, dessa forma, demonstrar os efeitos de viabilidade gerados pelos benefícios fiscais. Contudo, percebeu-se que os indicadores TIR e VPL sofreram impactos positivos significativos, quando aplicados o Fundopem/RS

Teoria e Evidência Econômica - a. 24, n. 50, p. 89-112, jan./jun. 2018 
e o Integrar/RS. Da riqueza gerada pelo projeto sem incentivos fiscais (VPL de $\mathrm{R} \$$ 90.629.555,89 e TIR de 36,26\%), o enquadramento no Fundopem/RS beneficia a empresa com a geração de uma riqueza extra (transferida pelo estado para a empresa) de $\mathrm{R} \$$ 9.920.051,72 (VPL de $\mathrm{R} \$ 100.549 .607,61$ e TIR de 46,13\%); e, se o enquadramento permitir o acesso ao Integrar/RS, a riqueza extra gerada para os sócios da cooperativa é de $\mathrm{R} \$ 16.829 .708,60$ (VPL de $\mathrm{R} \$ 107.459 .264,49$ e TIR de $46,47 \%)$.

Conclui-se que ambos os incentivos proporcionam benefícios significativos no fluxo de caixa da empresa beneficiária, o que mostra a efetividade e a importância dos incentivos para o aumento da produção e de emprego nas empresas localizadas no território estadual. 


\title{
Analysis of the program of tax incentives from the state of Rio Grande do Sul Fundopem/RS and Integrar/RS for a cooperative in the Region Northeast
}

\begin{abstract}
This article has for objective to analyze the importance and the effectiveness of the fiscal incentives Fundopem/RS and Integrar/RS of the state of Rio Grande do Sul, in Brazil, through the impact generated in the cash flow in the project of expansion of a cooperative located in the North of the state for to agriculture industrialization of the corn in its transformation in syrup for one industry of candies. It was verified that the fiscal incentives present significant positive impacts measured for the indicators economical financiers of the Intern Return Rate (IRR) and Net Presente Value (NPV). The wealth generated by the project of investment of 40 million of reais, without the fiscal incentives, it measured for NPV was of $R \$ 90.629 .555,89$, with a profitability measured by IRR of $36,26 \%$, considering an opportunity cost from $8 \%$ a year. The framing in Fundopem/RS benefits the company with the generation of an extra wealth of $\mathrm{R} \$ 9.920 .051,72$ (NPV of $\mathrm{R} \$ 100.549 .607,61$ and IRR of $46,13 \%$ ) and the framing when Integrar/RS, generates an extra wealth for the partners of the cooperative would be of $R \$ 16.829 .708,60$ (NPV of $R \$ 107.459 .264,49$ and IRR of $46,47 \%)$.
\end{abstract}

Keywords: Fundopem/RS. Fiscal incentives. Integrar/RS.

\section{Análisis del programa de incentivos fiscales del estado de Rio Grande do Sul Fundopem/RS e Integrar/RS para una cooperativa en la Región Noreste}

\section{Resumen}

Este artículo tiene como objetivo analizar y demostrar la importancia y la eficacia de los incentivos fiscales Fundopem/RS e Integrar/RS, a través del impacto generado en el flujo de caja en el proyecto de ampliación de una cooperativa situada en el norte de Rio Grande do Sul a las industrialización agro de procesamiento de maíz aceite de maíz industria del jarabe para los dulces y dulces dentro del estado. Se encontró que los incentivos fiscales tienen efectos positivos significativos medidos por los indicadores económicos financieros Tasa Interna de Retorno (TIR) y Valor Actual Neto (VAN). La riqueza generada por el proyecto de inversión de 40 millones de reales, sin incentivos fiscales, medida por el VAN de $\mathrm{R} \$ 90,629,555.89$ con una rentabilidad del $36,26 \%$, medido por TIR, considerando un costo de $8 \%$ anual. El marco en el Fundopem/RS beneficia a la empresa con la generación de una riqueza adicional de $\mathrm{R} \$ 9,920,051.72$ (VAN de $\mathrm{R} \$ 100,549,607.61$ y la TIR del $46,13 \%$ ) y el marco para Integrar/RS genera riqueza adicional para los miembros de la cooperativa sería de $\mathrm{R} \$ 16,829,708.60$ (VAN de $\mathrm{R} \$ 107,459,264.49$ y la TIR del 46,47\%).

Palabras clave: Fundopem/RS. Incentivos fiscales. Integrar/RS. 


\section{Referências}

FERRAZ, João Carlos; PAULA, Germano Mendes de; KUPFER, David. Política industrial. In: KUPFER, David; HASENCLEVER, Lia. Economia industrial: fundamentos teóricos e práticos no Brasil. Rio de Janeiro: Elsevier, 2002. p. 545-567.

FILIPPIN, Flávia. O novo Fundopem / RS: uma análise das mudanças introduzidas e dos projetos enquadrados no novo formato. 2012. 90 f. Monografia (Graduação em Economia) - Faculdade de Ciências Econômicas, Universidade Federal do Rio Grande do Sul, Porto Alegre, 2012.

GIAMBIAGI, Fábio; ALÉM, Ana Cláudia Duarte de. Finanças públicas: teoria e prática no Brasil. 4. ed. Rio de Janeiro: Elsevier, 2011.

RIBAS JUNIOR, Darvin. Fundopem/RS: análise do funcionamento e controle do incentivo. 2004. 140 f. Monografia (Especialização em Gestão Fazendária) - Pós-Graduação de Gestão Fazendária, Centro de Ensino à Distância, Pontifica Universidade Católica do Rio Grande do Sul, Porto Alegre, 2004.

RIO GRANDE DO SUL. Decreto $n^{\circ}$ 49.205, de 11 de junho de 2012. 2012. Disponível em: <http://www.al.rs.gov.br/legis/M010/M0100099.ASP?Hid_Tipo=TEXTO\&Hid_TodasNormas $=57836 \& h T e x t o=\& H i d \_I D N o r m a=57836>$. Acesso em: 1 jan. 2016 .

. Lei $n^{\circ}$ 6.497, de 20 de dezembro de 1972. 1972. Disponível em: <http://www.al.rs.gov.br/ legis/M010/M0100018.asp?Hid_IdNorma=35765\&Texto=\&Origem=1>. Acesso em: 1 jan. 2016.

Lei $n^{\circ}$ 13.708, de 06 de abril de 2011. 2011a. Disponível em: <http://www.al.rs.gov.br/ legis/M010/M0100099.ASP?Hid_Tipo=TEXTO\&Hid_TodasNormas=55979\&hTexto=\&Hid_IDNorma $=55979>$. Acesso em: 1 jan. 2016.

. Lei $n^{\circ}$ 13.843, de 05 de dezembro de 2011. 2011b. Disponível em: <http://www.al.rs.gov.br/ legis/M010/M0100099.ASP?Hid_Tipo=TEXTO\&Hid_TodasNormas=57032\&hTexto=\&Hid_IDNorma $=57032>$. Acesso em: 1 jan. 2016.

. Lei $n^{\circ}$ 11.916, de 08 de maio de 2003. 2003. Disponível em: <http://www.al.rs.gov.br/legis/M010/M0100099.ASP?Hid_Tipo=TEXTO\&Hid_TodasNormas=46371\&hTexto=\&Hid_IDNorma $=46371>$. Acesso em: 1 jan. 2016.

Secretaria do Desenvolvimento Econômico, Ciência e Tecnologia. Resolução Normativa $\overline{n^{\circ} 1,2}$ e 3. 2016. Disponível em: <http://www.saladoinvestidor.rs.gov.br/conteudo/1427/?FUNDOPEM\%252FRS_e_INTEGRAR\%252FRS>. Acesso em: 1 jan. 2016.

SILVA NETO, A. L. Tópicos especiais em avaliação financeira de projetos. Viçosa: Universidade Federal de Viçosa, 1994. (Apostila n 346 ). 